New Zealand journal of industrial relations, 1986, 11, 91-104

\title{
Changing retirement patterns in New Zealand, 1976 and 1981
}

\author{
Mike Rochford*
}

In New Zealand, as in many developed countries, the general trend this century has been towards earlier retirement. This trend has accelerated since the 1960 s. Between 1976 and 1981 the shift to earlier retirement was characterised by an increase in retirement at the age of 60 and a decrease in retirement at the age of 65 . Female retirement patterns became increasingly similar to male retirement patterns. The effect of the introduction of National Superannuation on retirement patterns is a question which is addressed in this paper.

\section{Introduction}

This study looks at the retirement patterns revealed by the 1976 and 1981 Censuses. With the introduction of National Superannuation over the 1977-1978 period, people over 60 received a universal benefit set at a higher level than the previous income-tested Age Benefit. Prior to the introduction of National Superannuation, the Research Section of the Department of Social Welfare considered the possible effect on retirement patterns. It was suggested that the higher level of National Superannuation might encourage retirement by providing a more attractive retirement income.

The removal of the income test was seen as having 2 possible effects. By removing the stigma associated with an income tested benefit, the introduction of National Superannuation might have allowed some people, who were previously reluctant to go on to the Age Benefit, to retire earlier. Conversely, the removal of the income test might have increased labour force participation by removing the benefit abatement disincentive on extra earnings. Those who chose to remain in the work force had the prospect of a substantial boost in income (earned income plus 80 percent of the average wage for a married couple aged over 60 ), allowing, perhaps, for a higher level of savings.

It was not known what the net result of these possible effects would be on labour force participation, but it was tentatively suggested that, overall, National Superannuation would decrease labour force participation. It was decided to monitor retirement trends. In 1976, a request was sent to the Department of Statistics for Census tables of labour force participation of the population aged 50 years and over for the period 1961-1981. Tables from 1961, 1966 and 1971 were not available. but by 1984 tables from the 1976 and 1981 Censuses had been received. These tables form the basis of the present study.

The focus of this study is the pattern of retirement in 1976 and 1981 and the changes over that period. The influence of National Superannuation on retirement patterns cannot be determined with any certainty from a study of Census data such as these. Any change in retirement patterns can only be attributed to National Superannuation in combination with all the other factors which affect retirement. Determining precisely the importance of National Superannuation relative to the other factors is beyond the scope of this study.

Retirement can be a gradual process for some people, starting with a reduction in working hours in a current job, or a switch from a full-time to a part-time job, until eventually there is a complete withdrawal from the labour force. This study concentrates on withdrawal from the full-time labour force where full-time is defined as employment for 30 hours or more per week. but some consideration is also given to part-time employment and reduced working hours in

* Research Officer. Research Section, Department of Social Welfare 
full-time employment. Unless otherwise stated, the term "retirement" in this study refers to withdrawal from the full-time labour force.

\section{Method}

The Census tables on which this study is based were drawn from the complete Census files of 1976 and 1981. The numbers presented in this report, therefore, are not sample estimates but actual population figures.

Because tables could not be obtained from the 1961-1971 Censuses, published Census data were used for a broad comparison of 1961-1981 retirement data in the first table (Table 1). For this table only, the labour force includes those unemployed and seeking work as well as those engaged for 20 hours per week or more. Figures are drawn to the same scale to allow for comparison.

Because "hours of employment" is the main variable used, this study ignores the difference between those who were retired and those who were unemployed or not employed for some other reason. This assumption, that all those not employed were retired, is not unreasonable for people in older age groups. In 1981, only 0.1 percent of males and 0.03 percent of females over the age of 60 classified themselves as "unemployed seeking work" (Department of Statistics, 1983). Of males over the age of 60 not in the full-time or part-time labour force, 97.5 percent classified themselves as "retired". Of females over the age of 60 not in the full-time or part-time labour force, 54.8 percent classified themselves as "retired" and 42.9 percent classified themselves as having "unpaid household duties" (a total of 97.7 percent).

National Superannuation was introduced in February 1977 at a rate for married couples based on 70 percent of the average ordinary time wage. In August 1978 (which is close to the mid-point of the 1976-1981 inter-censal period) the married couple rate was increased to 80 percent of the average ordinary time wage. Single people received 60 percent of the married couple rate.

\section{Results}

Table 1 shows the percentage of different age groups in the labour force over the 1961-1981 period. For males the 1961-1971 pattern was fairly stable except for a small move towards later retirement evident in 1966. Since 1971 a move towards earlier retirement has been clearly apparent. For females the general trend from 1961 to 1971 was for increased labour force participation. Since 1971 a trend towards earlier retirement was evident for females aged 60 and over, but participation rates for females aged 50-59 continued to increase.

Turning to the 1976 and 1.981 data, Table 2 gives the percentages in the full-time labour force ( 30 hours or more per week) by single years of age for males, females and never-married females. Figure 1 graphs these data, while Figures 2 and 3 show the full-time percentage change by single years of age. For each year of age, percentage change is measured by the difference between the percentage engaged full-time at that year of age and the percentage engaged full-time at the age one year younger. Figures 2 and 3 can be thought of as illustrating the distribution of retirement ages for males and females respectively.

\section{Males}

It is clear that by 1981 more males were retiring atthe age of 60 than was the case in 1976. To summarise the 1981 pattern for males (Table 2), 21 percent had retired at the age of 59,44 percent had retired at age 60 , and 53 percent had retired at the age of 61 . By comparison, in 1976, 17 percent had retired at the age of 59,34 percent had retired at the age of 60 , and 41 percent had retired at the age of 61 .

Figure 2 shows that 60 was easily the most common retiring age for males in 1981. In 1976, 60 was only slightly more common than 65 . Prior to 1976,65 was the most common retiring age (Department of Statistics, 1970, 1977).

The age at which 50 percent of the population has retired and 50 percent is still in the fulltime labour force can be considered the median retiring age. Taking the mid-point of each age year and assuming a smooth transition from one year to the next, median retirement ages can be calculated. In 1976 the median retirement age for males was 63 years and 3 months. In 1981 
it was 61 years and 2 months. To generalise from this, males in 1981 were retiring about 2 years earlier than in 1976.

Other data indicate (Department of Statistics, 1977) that in 1971 the median retirement age for males was just over 65 years. This suggests that the sharp move towards earlier retirement was just as strong over the 1971-1976 period as it was over the 1976-1981 period. Table 1 supports this view. A continued decline in median retirement age for males of the magnitude of the 1971-1981 decline of 4 years seems unlikely. This is because 59-year-old males maintained a high level of labour force participation between 1976 and 1981. If the median age did fall another 4 years over the 1981-1991 period it would be about 57 years by 1991. A more likely scenario is that the median will fall to 60 years in 1986 and remain at 60 in 1991. Given past trends in retirement before the age of $60,25-30$ percent of the male population aged 59 in 1991 will have retired ( $\mathrm{cf} 21$ percent in 1981). It seems unlikely that more than 50 percent of males will retire before the age of 60 for some years yet.

However, a shift away from 65 and towards 60 as a retirement age is likely to continue. This was the major trend for males over the 1976-1981 period.

\section{Females}

The pattern of withdrawal of females from the labour force was very different from that of males (Table 2). Most females had withdrawn from the full-time labour force before the age of 50 . Some may never have been in the paid labour force. Many probably withdrew from the paid labour force with the advent of marriage or their first child and it seems that most never returned to sustained full-time paid work.

However, this is changing, as a comparison of 1976 and 1981 figures shows. Labour force participation increased between 1976 and 1981 for females aged 50-59 as increasing numbers of females returned to the paid labour force after family responsibilities had lessened. This trend can only be expected to continue, particularly as generations of women with higher educational qualifications and smaller families move into this age group.

For those women who were in full-time employment in their late fifties, 60 became an increasingly significant retirement age, as Figure 3 shows. The age of 65 was relatively unimportant, and became less so by 1981 . This might be expected, given that only 5.5 percent of females were still in the full-time labour force at the age of 64 (1981). Females were more likely than males to retire while aged 50-59.

Never married females were examined separately because it was expected that their retirement pattern would be closer to that of males than to that of other females. Table 2 and Figures 1 and 4 show that this was the case, although there were some interesting differences.

Firstly, at age 50, never married females had a rate of full-time labour force participation which was below that of males at age 50 . Secondly, the rate declined over the ages $50-59$ faster than for males, so that by age 59 half of all never married females had withdrawn from the fulltime labour force. However, females generally had a higher rate of part-time employment than males in the 50-59 age group (see Table 5), and this was also true for never married females.

As with males, 60 was easily the most common retirement age for never married females, and it became more common between 1976 and 1981 .

\section{Employment status}

The employment status of males employed full-time was examined by single years of age, 1976 and 1981. The percentage of males employed full-time who were wage or salary earners (as opposed to self-employed) generally increased with each year of age between the ages of 50 and 59. This pattern was more pronounced in 1981 than in 1976. This indicates an increasing tendency for some self-employed workers to retire earlier than wage or salary earners (assuming that mortality rates were similar for both groups).

The percentage of wage or salary earners remaining in full-time employment generally decreased with each year of age after the age of 59. This indicates that proportionately more self-employed workers than wage or salary earners retired late in life. It appears that for selfemployed workers retirement was spread over a wider range of ages. The ages of 60 and 65 were not as important for retiring self-employed workers as they were for wage or salary earners. In 1981 there was greater divergence between the retirement pattern of the self-employed worker and that of the wage or salary earner. This suggests that the general move towards earlier retirement applied more to wage or salary earners than it did to self-employed workers. The 
shift away from 65 and towards 60 as a retirement age has had less effect on self-employed workers. This implies that employers' retirement policies could be a major factor in the move towards earlier retirement. Self-employed workers have fewer constraints on their choice of retirement age.

The 2 types of self-employed workers, those with employees and those without employees, showed generally similar patterns in 1976. In 1981, however, a tendency emerged for the selfemployed with employees to retire earlier than the self-employed without employees. Whether this is the start of a long term trend remains to be seen.

\section{Occupational group}

For males employed full-time a table was produced of minor occupational group by single years of age. The 27 most common occupational groups were examined for differences in retirement patterns. There was a problem with these data in that the former occupations of those already retired were not known. Therefore it was not possible to determine what proportion of those in a particular occupation had retired by a particular age. Different rates of decline with age in occupations could be due to different mortality rates or changing demand for some occupations in the past. It was decided to look at the ages 59 to 61 only, since a sharp decline in numbers in an occupation around the age of 60 can be assumed to be mainly due to retirement rather than mortality or historical labour demand conditions.

Table 3 shows those occupations which moved most strongly towards retirement at age 60 during the 1976-1981 period, as well as those which moved least strongly.

The bookkeepers, cashiers and related workers group appears to have made the greatest move towards retirement at age 60 . In 1981 there were 14616 males of all ages in this group, which included bank officers, accounts clerks and wages clerks. In 1976 this was the group which had the least indication of retirement at age 60, but in 1981 it was close to the average. Of the 5 occupational groups which showed the greatest shift between 1976 and 1981 towards retirement at age 60,4 could be described as white-collar groups: technical sales staff, commercial travellers and manufacturers' agents; architects, engineers and related technicians; clerical and related workers; and bookkeepers, cashiers and related workers. The exception was the electrical fitters and related electrical and electronics workers group (which included linemen and registered electricians). By 1981 this group had become one of the groups from which retirement at age 60 was most likely. Many in this group were employed by government departments or local authorities, and therefore may have been affected by their compulsory retirement policies.

The 5 occupational groups which showed the least shift towards retirement at 60 included 2 groups largely composed of self-employed workers: farmers, and working proprietors (wholesale and retail trade).

The other 3 groups were: food and beverage processors; building caretakers, charworkers, cleaners and related workers; and government executive officials. The inclusion of government officials may seem surprising, given that a compulsory retirement age of 60 was introduced for government servants whose employment began after 1962. Most government executive officials reaching the age of 60 in the 1976-1981 period may have joined the government service prior to 1962 and it may be another 10 years or more before the majority of Government servants are required to retire at age 60 .

The building caretakers etc group is one which many males join late in their working life. In fact there were 31 percent more 59 -year-olds in this group than there were 50 -year-olds (1981). Since many in this group had only recently switched to this work, a shift towards reitrement at 60 would not be expected.

The food and beverage processors group (of which freezing workers were the largest component) showed no shift towards retirement at 60 , unlike most production workers. By 1981 food and beverage processors were a relatively late retiring group, perhaps reflecting particular conditions of employment in the food and beverage industries.

The occupational group which had the sharpest drop in numbers of people aged 60 , in both 1976 and 1981, was the painters. In 1981, the number of painters aged 61 was only one third of the number aged 59. Technical sales staff, commercial travellers and manufacturers' agents were second most likely to retire at age 60 in 1981, following a big shift towards retirement at 60 between 1976 and 1981 . 
Table 4 shows the number of 61-year-old males in a major occupational group as a percentage of the number of 59-year-olds for the 7 major occupational groups, 1976 and 1981. The change in this percentage between 1976 and 1981 is also shown. This table indicates that the professional, technical and related workers group made the greatest move towards earlier retirement, while the agricultural, animal husbandry and forestry workers, fishermen and hunters group made the smallest. The agricultural etc group was the only major group in which the majority of workers were self-employed. With the other 6 major groups, which are largely composed of wage or salary earners, a trend can be discerned. Those groups from which retirement was least likely at age 60 in 1976 had made the greatest move towards retirement at age 60 by 1981 . Thus there seems to have been a trend towards uniformity of male retirement patterns across different occupational groups, but only for wage or salary earners.

Table 4 also shows that the 1976-1981 move towards earlier retirement at age 60 was much stronger for wage and salary earning males than it was for self-employed males. This illustrates the increased divergence between wage and salary earners' and self-employed workers' retirement patterns.

In 1976 the 61 year old cohort of males was larger relative to the 59 year old cohort than was the case in 1981, and this should be noted when making comparisons.

\section{Part-time employment and reduced hours of employment}

So far in this study only withdrawal from the full-time labour force ( 30 hours or more per week) has been considered. Retirement from the part-time labour force and reduction in hours of employment are also of interest. Table 5 shows part-time employment by single years of age, 1976 and 1981, for females and males.

At age 50 females had a high level of part-time employment compared with males. The proportion of females employed part-time fell steadily from age 50 onwards. However, from age 64 onwards there were more females employed part-time than full-time (1981). This was because retirement from the full-time labour force occurred at a faster rate than retirement from the part-time labour force from the age of 60 onwards. This may have been partly because some females moved from full-time employment to part-time employment before retiring completely.

Looking at the 2 categories of part-time working hours by single years of age, it is clear that for females withdrawal from the 20-29 hours per week category occurred at a faster rate than withdrawal from the 1-19 hours per week category. The 2 categories of full-time working hours examined (30-39 hours, 40 or more hours) both showed similar rates of decrease to each other, so there was no clear evidence of reductions in full-time working hours as part of the female retirement process. If there had been a significant movement from the 40 or more hours category to the 30-39 hours category, it might be expected that the percentage in the 30-39 hours category would have increased with age or had a slower rate of decrease, but this was not the case.

The increase in female participation in the labour force which occurred in the 50-59 age group between 1976 and 1981 was greatest for those employed for 1-19 hours per week. For females over 60 years there was little change in the proportion employed part-time between 1976 and 1981.

Participation in the part-time labour force was negligible among 50 year old males, but rose steadily with each successive year of age until the age of 67 years. Nevertheless, even at the peak age of 67 , less than 8 percent of males were in the part-time labour force. It seems that the great majority of retiring males made the transition directly from full-time working hours to nil working hours. However, a certain proportion of males did move from full-time employment to part-time employment as part of their retirement process. After the age of 67 involvement in the part-time labour force steadily decreased.

Females decreased their part-time labour force participation over the same age range (5067) within which male part-time labour force participation was increasing. At age 50 many more females were employed part-time than males, but at later ages a point was reached when a higher proportion of males were employed part-time than females. In 1976 this point was age 64 , but in 1981 it was age 62 (see Table 5). This shift can be attributed to an increase in part-time labour force participation for males aged 60-64 in 1981 compared with 1976. Earlier entry of males into the part-time labour force was to be expected in conjunction with the earlier retirement from the full-time labour force which occurred in 1981. 
For males aged 60-69 employed part-time, the 3 most common occupations in 1981 were: building caretakers, charworkers, cleaners and related workers; clerical and related workers; and agricultural and animal husbandry workers. For females aged 60-69 employed part-time the 3 most common occupations in 1981 were: salespersons, shop assistants and related workers; clerical and related workers; and cooks, waitresses, bartenders and related workers.

Examining 2 categories of full-time working hours for males, the proportion working 30-39 hours increased over the age range 50-55. This indicates that there was some movement towards reduced working hours among older male full-time workers. The reductions could have occurred in current jobs or may have been caused by workers switching to jobs with fewer working hours.

After the age of 55 years, the percentage of males employed for 30-39 hours declined, but the rate of decline was less than for those employed for 40 hours or more. For example, in 1981 , 55-year-old males employed 30-39 hours made up 10.7 percent of all 55 year old males employed for 30 hours or more per week. By the age of 65 , males employed $30-39$ hours made up 18.1 percent of all males employed for 30 hours or more.

Between 1976 and 1981 there were small increases in the proportions of males employed part-time or for 30-39 hours over most ages. These increases were too small to have much effect on the prevailing retirement pattern in both 1976 and 1981, which was a transition from employment for 40 hours or more per week to no employment at all. This prevailing pattern is illustrated by comparing 61-year-old males with 59 -year-old males in 1981. Between the ages of 59 and 61 the rate of males employed for 40 hours or more decreased by 29.6 percentage points while the proportion employed for nil hours increased by exactly the same amount. The rate of males employed 1-29 hours increased by only 2.8 percentage points while those employed $30-39$ hours decreased by 2.7 percentage points. Clearly, most males who withdrew from employment at 40 hours or more per week, between the ages of 59 and 61, had reduced their hours of employment to nil by the age of 61 . For these workers, any transitional period of employment for less than 40 hours per week was either non-existent or of very short duration.

\section{Conclusion}

Between 1976 and 1981 there was a strong move towards earlier retirement. This move was characterised by a shift away from a retirement age of 65 and towards a retirement age of 60 . This 1976-1981 trend was much stronger for wage or salary earning males than it was for selfemployed males, suggesting that factors unique to wage or salary earners were the major factors responsible for the trend. This implies that the introduction of National Superannuation, a universal measure applicable to wage or salary earners and self-employed workers alike, was not the major factor responsible for the trend. The 1976-1981 trend was a continuation of the 1971-1976 trend (as Table 1 shows), which also suggests that the introduction of National Superannuation in 1977 was not the major factor behind the move towards earlier retirement.

All that can be said about the introduction of National Superannuation is that it appeared to have no great impact on the existing trend towards ealier retirement, neither speeding it up nor slowing it down significantly. It is possible that National Superannuation did have a major impact on retirement but that this was disguised by another major factor introduced in the same time period but acting in the opposite direction. In the absence of a plausible model identifying this other factor, however, it might be tentatively assumed that the introduction of National Superannuation had no major impact on retirement trends.

A move towards earlier retirement occurred in most developed countries during the $1970 \mathrm{~s}$, and the changes in retirement in New Zealand were in line with overseas trends (Bureau of Labour Market Research, 1983, Appendix I). Australia's pattern was particularly similar to New Zealand's, which also argues against the influence of National Superannuation since no similar scheme was introduced in Australia (Jones, 1984, pp 52-53). 
Table 1: Age-specific labour force participation rates 1961-1981 censuses

\begin{tabular}{lrrrrr}
\hline & \multicolumn{5}{c}{ Males } \\
Age Group & 1961 & 1966 & 1971 & 1976 & 1981 \\
$50-54$ & 96.6 & 96.8 & 96.3 & 95.9 & 95.2 \\
$55-59$ & 91.6 & 92.7 & 92.1 & 90.5 & 88.9 \\
$60-64$ & 69.0 & 71.9 & 69.2 & 57.9 & 46.7 \\
$65-69$ & 39.1 & 42.1 & 36.1 & 26.7 & 18.1 \\
$70-74$ & 20.7 & 19.3 & 17.5 & 12.4 & 9.4 \\
$75+$ & 7.4 & 6.9 & 5.2 & 4.9 & 3.8 \\
& & & Females & & \\
Age Group & 1961 & 1966 & 1971 & 1976 & 1981 \\
$50-54$ & 27.7 & 31.4 & 35.2 & 40.6 & 44.3 \\
$55-59$ & 22.1 & 25.4 & 27.5 & 29.0 & 31.6 \\
$60-64$ & 12.7 & 14.6 & 15.5 & 13.9 & 12.1 \\
$65-69$ & 6.5 & 7.3 & 7.2 & 5.6 & 3.9 \\
$70-74$ & 2.8 & 3.1 & 2.7 & 2.1 & 1.5 \\
$75+$ & 1.0 & 1.1 & 0.8 & 0.6 & 0.5 \\
& & & & & \\
\hline
\end{tabular}

Table 2: Percentage engaged full-time in the labour force by single years of age (1976 and 1981)

\begin{tabular}{|c|c|c|c|c|c|c|}
\hline \multirow[b]{2}{*}{ Age in Years } & \multicolumn{2}{|c|}{ MALES } & \multicolumn{2}{|c|}{ FEMALES } & \multicolumn{2}{|c|}{$\begin{array}{l}\text { NEVER MARRIED } \\
\text { FEMALES }\end{array}$} \\
\hline & 1976 & 1981 & 1976 & 1981 & 1976 & 1981 \\
\hline 50 & 95.3 & 93.4 & 33.8 & 36.8 & 68.3 & 69.3 \\
\hline 51 & 94.5 & 93.1 & 33.1 & 35.4 & 68.9 & 66.7 \\
\hline 52 & 94.1 & 92.4 & 31.6 & 33.6 & 69.0 & 65.3 \\
\hline 53 & 93.3 & 91.8 & 30.0 & 32.3 & 64.6 & 66.7 \\
\hline 54 & 92.4 & 90.5 & 29.6 & 30.3 & 66.6 & 67.5 \\
\hline 55 & 91.9 & 89.7 & 26.9 & 28.6 & 62.5 & 59.0 \\
\hline 56 & 90.3 & 88.3 & 24.9 & 26.9 & 55.6 & 57.8 \\
\hline 57 & 87.9 & 85.3 & 22.1 & 24.0 & 53.2 & 57.6 \\
\hline 58 & 85.6 & 82.2 & 20.4 & 21.9 & 51.8 & 48.0 \\
\hline 59 & 83.2 & 79.0 & 18.1 & 19.9 & 48.4 & 50.2 \\
\hline 60 & 65.7 & 56.6 & 14.2 & 13.0 & 33.9 & 31.1 \\
\hline 61 & 58.8 & 46.7 & 11.9 & 10.6 & 29.8 & 24.8 \\
\hline 62 & 53.8 & 39.9 & 10.5 & 7.8 & 26.5 & 17.4 \\
\hline 63 & 48.7 & 35.8 & 8.9 & 6.7 & 23.2 & 16.5 \\
\hline 64 & 44.2 & 30.7 & 7.5 & 5.5 & 20.3 & 13.4 \\
\hline 65 & 28.6 & 19.7 & 5.3 & 3.8 & 12.2 & 9.0 \\
\hline 66 & 25.1 & 16.0 & 4.3 & 3.1 & 12.3 & 7.0 \\
\hline 67 & 21.4 & 13.3 & 3.4 & 2.0 & 9.5 & 5.1 \\
\hline 68 & 17.9 & 11.6 & 3.3 & 2.1 & 9.3 & 5.6 \\
\hline 69 & 16.7 & 10.5 & 2.5 & 1.8 & 6.6 & 4.4 \\
\hline 70 & 12.6 & 9.0 & 1.6 & 1.2 & 3.5 & 3.4 \\
\hline 71 & 10.7 & 7.9 & 1.5 & 0.9 & 4.8 & 2.1 \\
\hline 72 & 8.5 & 6.7 & 1.4 & 0.9 & 3.4 & 1.8 \\
\hline 73 & 7.8 & 5.5 & 0.9 & 0.8 & 2.0 & 1.9 \\
\hline 74 & 7.0 & 5.0 & 0.9 & 0.7 & 1.8 & 1.6 \\
\hline $75+$ & 3.3 & 2.6 & 0.4 & 0.4 & 0.9 & 1.3 \\
\hline
\end{tabular}


Table 3(a): Occupational groups which made the greatest move between 1976 and 1981 towards retirement at age 60 (full-time males)

1 Bookkeepers, cashiers and related workers

2 Technical sales staff, commercial travellers and manufacturers' agents

3 Electrical fitters and related electrical and electronics workers

4 Architects, engineers and related technicians

5 Clerical and related workers

Table 3(b): Occupational groups which made the least move between 1976 and 1981 towards retirement at age 60 (full-time males)

1 Working proprietors (wholesale and retail trade)

2 Food and beverage processors

3 Building caretakers, charworkers, cleaners and related workers

4 Farmers

5 Government executive officials

Table 4: 61 year olds as a percentage of 59 year olds in the major occupational groups, full-time males (1976 and 1981)

Major Occupational Group

Professional, technical \& related workers

Administrative \& managerial workers

Clerical and related workers

Sales workers

Service Workers

Agricultural, animal husbandry \& forestry workers, fishermen \& hunters

Production \& related workers, transport equipment operators \& labourers
1976

76.7

72.5

75.8

65.3

61.2

67.7

61.6

66.4

68.4

65.9
Percentage point 1981 change 1976-81

$\begin{array}{ll}49.6 & -27.1 \\ 49.2 & -23.3 \\ 54.7 & -21.1 \\ 52.6 & -12.7 \\ 46.0 & -15.2\end{array}$

62.4

46.7

$-14.9$

All occupational groups

50.6

$-15.8$

All self-employed workers

All wage or salary earners

61.9

48.1

$-6.5$

$-17.8$

93.4

85.5

$-7.9$ 
Table 5: Percentage engaged part-time in the labour force (1-29 hours per week) by single years of age (1976 and 1981)

\begin{tabular}{crrrr}
\hline & \multicolumn{2}{c}{ Females } & \multicolumn{2}{c}{ Males } \\
Age in Years & 1976 & 1981 & 1976 & 1981 \\
50 & 17.0 & 20.4 & 0.8 & 1.1 \\
51 & 17.1 & 20.2 & 0.8 & 1.2 \\
52 & 15.5 & 19.7 & 0.9 & 1.4 \\
53 & 14.9 & 18.4 & 1.0 & 1.4 \\
54 & 13.9 & 17.3 & 1.3 & 1.7 \\
55 & 13.3 & 16.5 & 1.3 & 1.6 \\
56 & 12.4 & 15.2 & 1.6 & 1.8 \\
57 & 11.8 & 13.8 & 1.6 & 2.0 \\
58 & 9.9 & 12.1 & 2.1 & 2.6 \\
59 & 9.4 & 10.6 & 2.2 & 3.0 \\
60 & 8.1 & 8.9 & 3.2 & 4.7 \\
61 & 7.5 & 7.7 & 4.2 & 5.9 \\
62 & 6.5 & 6.7 & 4.6 & 7.2 \\
63 & 5.6 & 6.4 & 4.9 & 6.9 \\
64 & 5.1 & 5.6 & 5.2 & 7.2 \\
65 & 4.2 & 4.6 & 6.3 & 7.1 \\
66 & 4.1 & 3.7 & 6.7 & 7.2 \\
67 & 3.6 & 3.6 & 7.3 & 7.7 \\
68 & 3.0 & 2.9 & 6.9 & 7.0 \\
69 & 2.5 & 2.4 & 6.5 & 6.2 \\
70 & 2.2 & 2.2 & 5.7 & 6.0 \\
71 & 1.6 & 1.7 & 5.9 & 5.0 \\
72 & 1.6 & 1.5 & 4.9 & 4.6 \\
73 & 1.5 & 1.1 & 4.1 & 4.2 \\
74 & 1.1 & 0.8 & 3.9 & 3.4 \\
75 & 0.4 & 0.4 & 2.2 & 2.0 \\
\hline & & & & \\
\hline
\end{tabular}


Figure 1: Percentage engaged full-time in the labour force by single years of age (1976 and 1981)

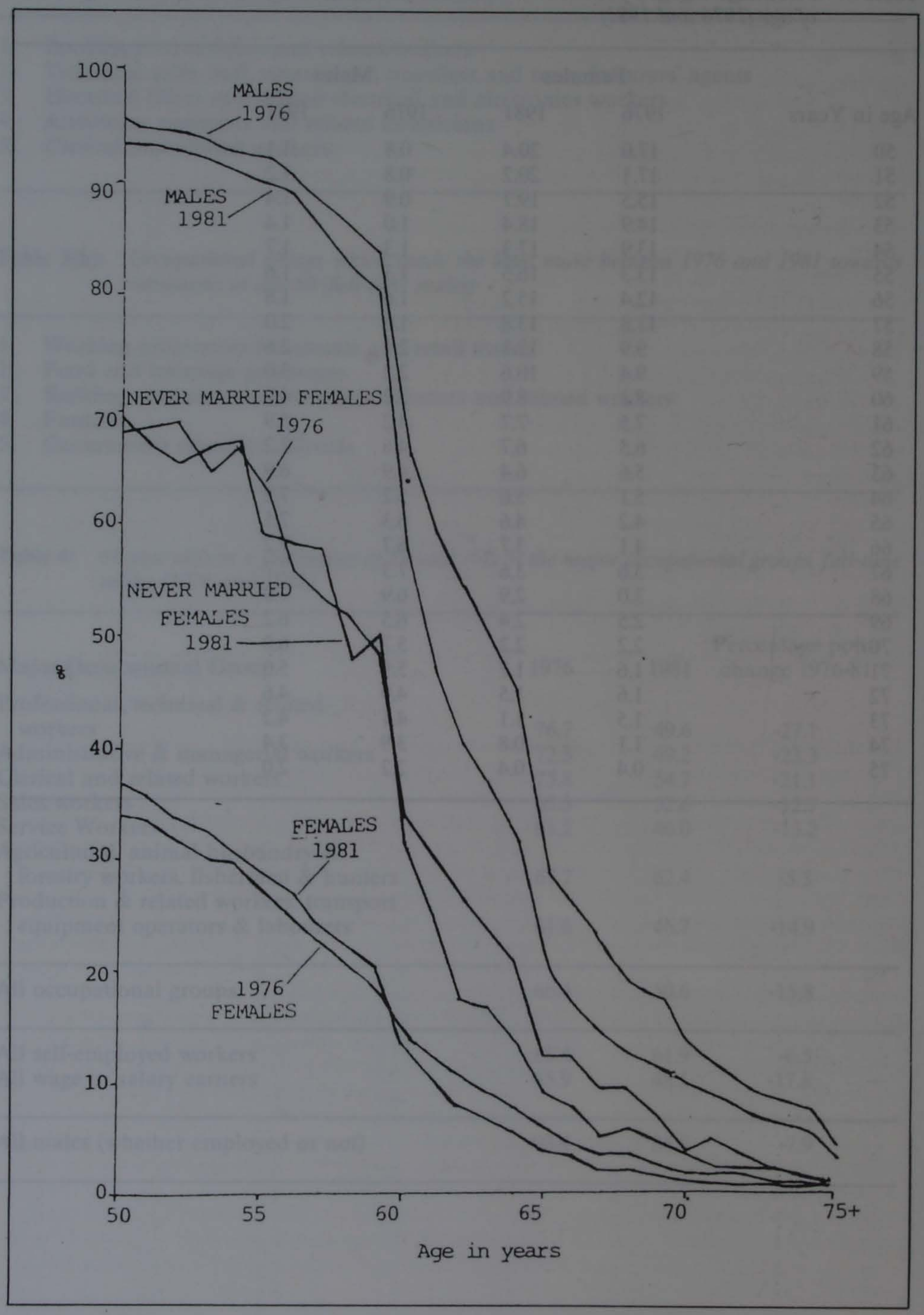


Figure 2: Percentage points change in the percentage of males engaged full-time in the labour force by single years of age (1976 and 1981)

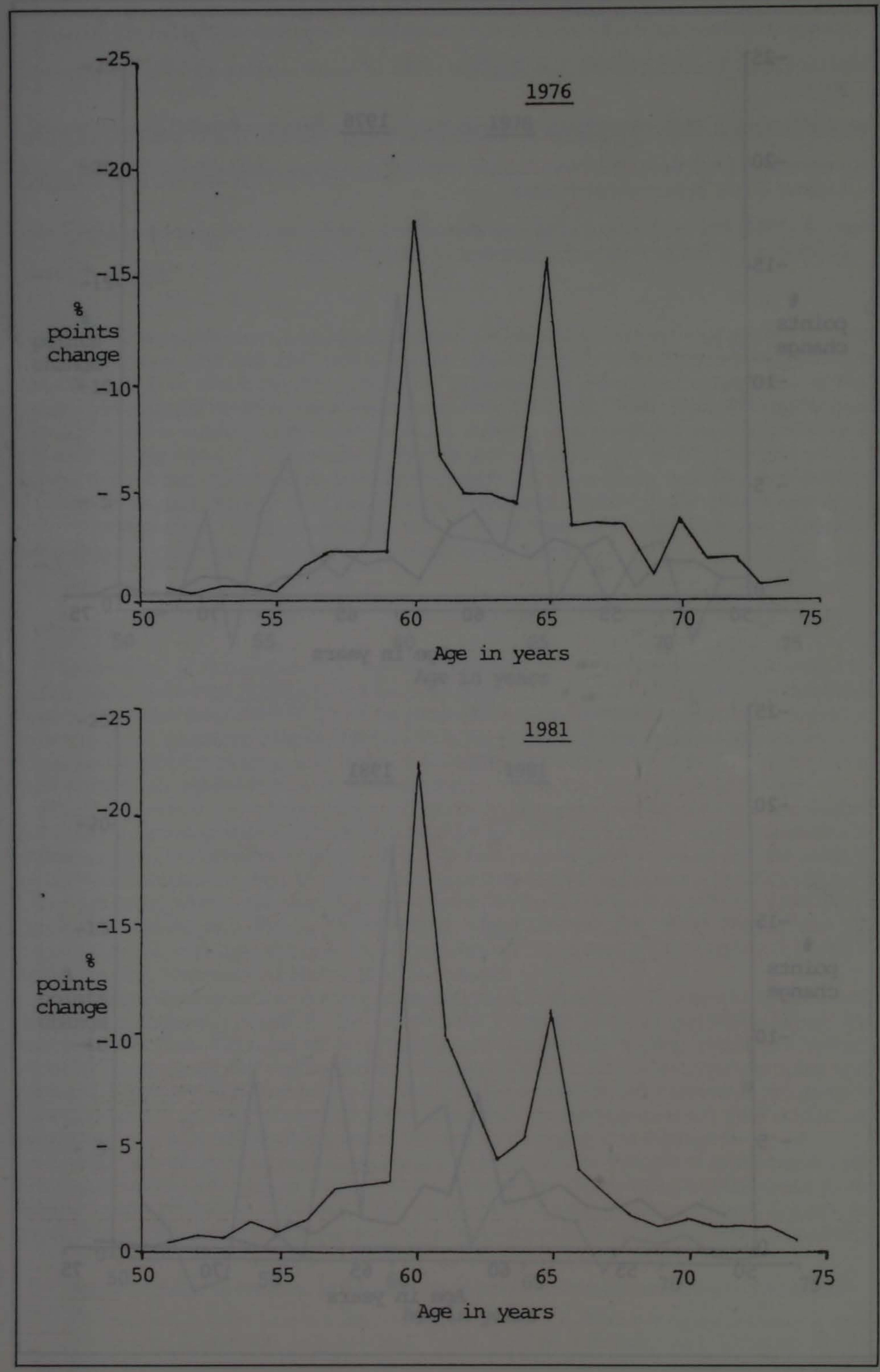


Figure 3: Percentage points change in the percentage of females engaged full-time in the labour force by single years of age (1976 and 1981)

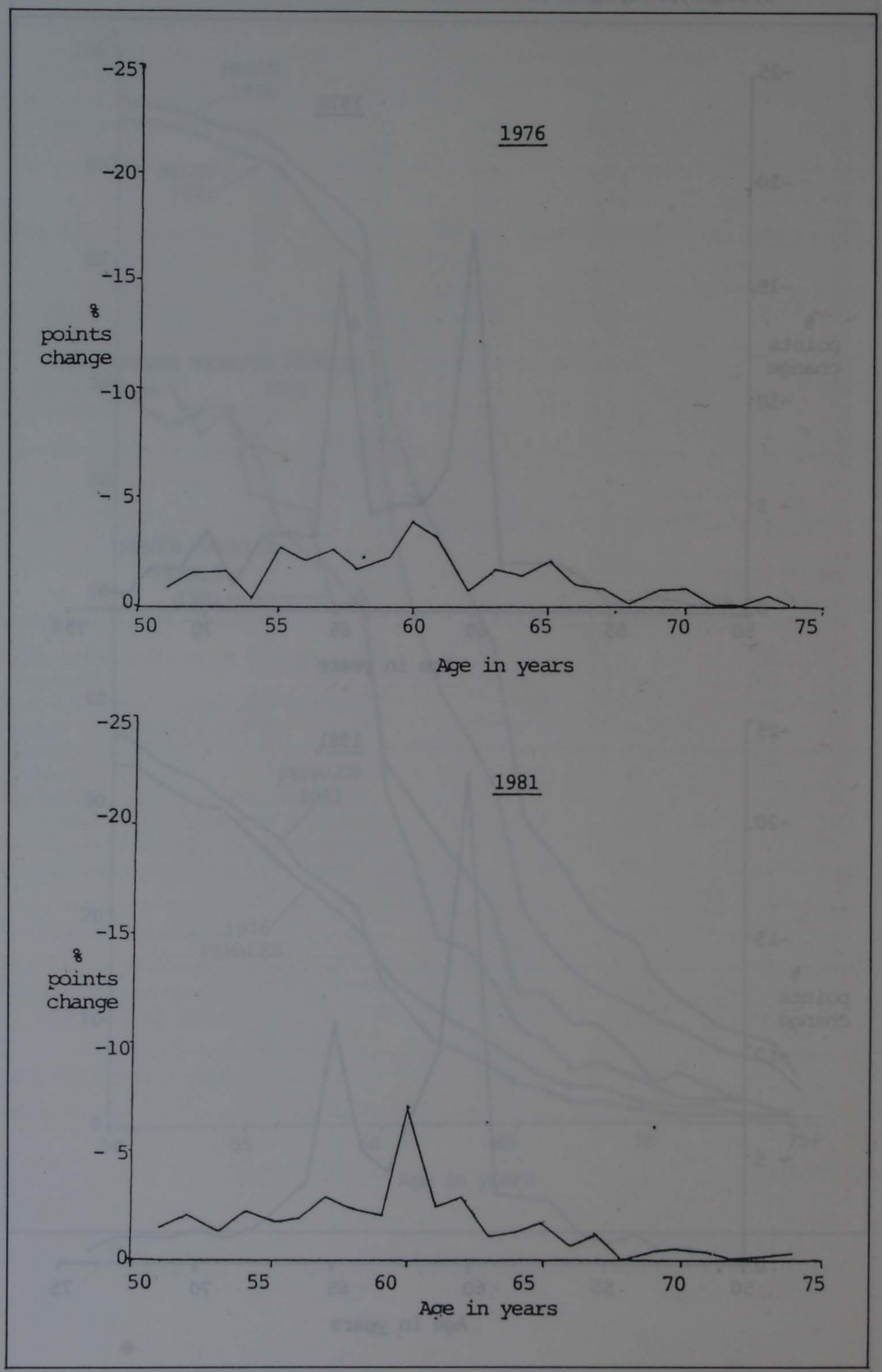


Figure 4: Percentage points change in the percentage of never-married females engaged full-time in the labour force by single years of age (1976 and 1981)

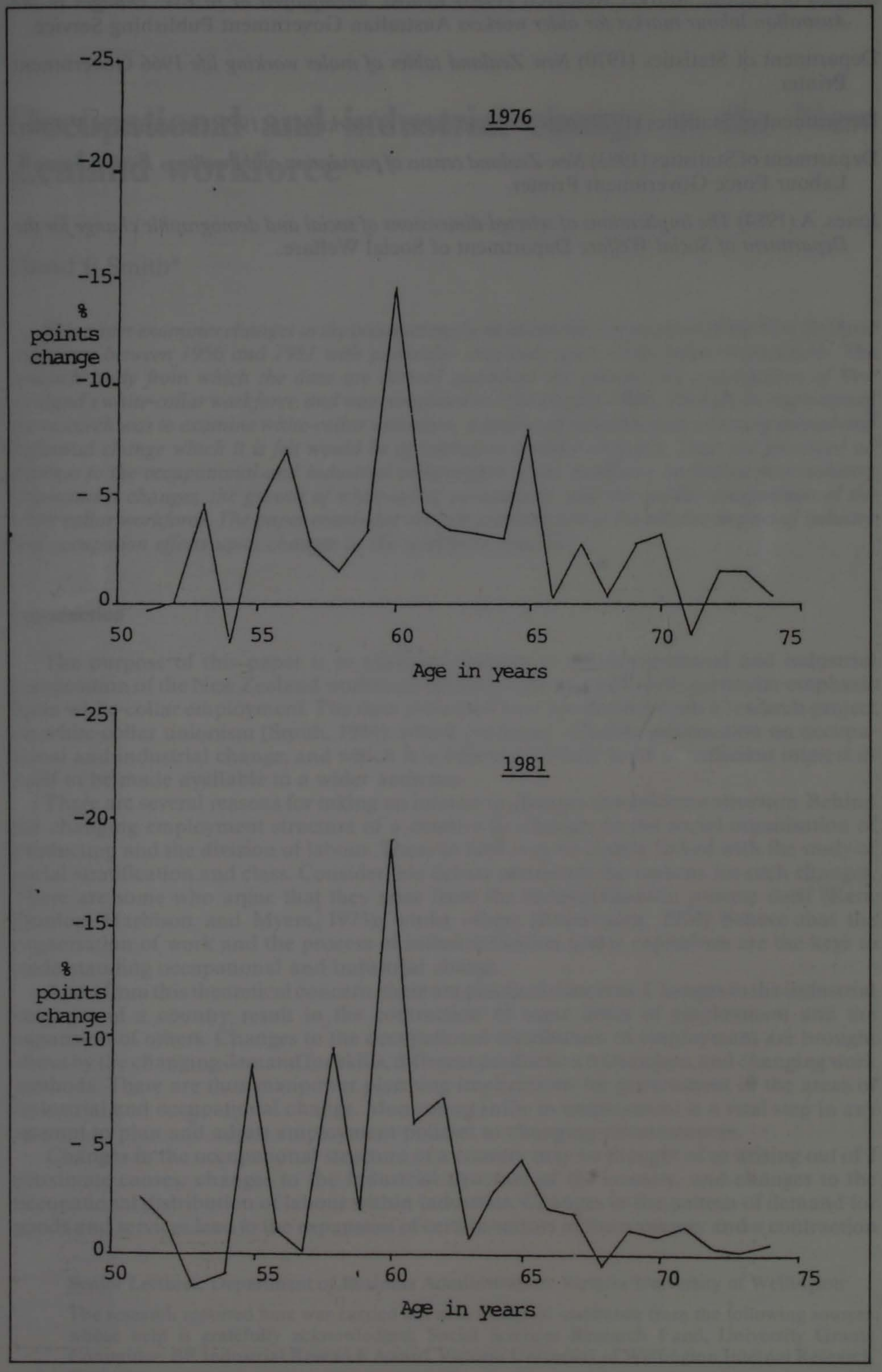




\section{Mike Rochford}

\section{References}

Bureau of Labour Market Research (1983) Retired, unemployed or at risk: changes in the Australian labour market for older workers Australian Government Publishing Service.

Department of Statistics (1970) New Zealand tables of males working life 1966 Government Printer.

Department of Statistics (1977) New Zealand tables of working life 1971 Government Printer.

Department of Statistics (1983) New Zealand census of population and dwellings 1981 Volume 4: Labour Force Government Printer.

Jones, A (1984) The implications of selected dimensions of social and demographic change for the Department of Social Welfare Department of Social Welfare. 